\title{
KURSI ERGONOMIS UNTUK MENURUNKAN KELELAHAN PADA PERAJIN PERAK DI KECAMATAN MANGGALA
}

\section{Ergonomic Chair To Reduce The Fatigue Silversmiths In District Manggala}

\author{
Januar Ariyanto, ${ }^{1}$ Syamsiar S Russeng, ${ }^{2}$ Mappeaty Nyorong ${ }^{3}$ \\ ${ }^{1}$ Program Studi Kesehatan Masyarakat Universitas Hasanuddin \\ ${ }^{2}$ Bagian Keselamatan dan Kesehatan Kerja, Fakultas Kesehatan Masyarakat, Universitas Hasanuddin \\ ${ }^{3}$ Bagian Promosi Kesehatan dan Ilmu Perilaku, Fakultas Kesehatan Masyarakat, Universitas Hasanuddin
}

Korespondensi: januaariyanto@gmail.com

\begin{abstract}
ABSTRAK
Sikap kerja yang tidak ergonomis merupakan salah satu penyebab kejadian kelelahan pada perajin perak. Penelitian ini bertujuan untuk mengetahui pengaruh kursi ergonomis terhadap penurunan kelelahan kerja berdasarkan respon asam laktat dan glukosa pada perajin perak. Desain penelitian ini adalah Quasi Eksperiment. Dengan jumlah sampel masing-masing 18 perajin perak pada kelompok kontrol dan perlakuan yang dipilih secara random sampling. Data yang dikumpulkan meliputi sikap kerja, kadar asam laktat dan glukosa sebelum dan sesudah bekerja. Analisis data berupa uji Wilcoxon dan Mann Whitney digunakan untuk menguji pengaruh kursi ergonomis terhadap penurunan kelelahan kerja pada perajin perak. Hasil penelitian menunujukan bahwa $30.6 \%$ responden berada pada $26-35$ tahun. 50\% responden memiliki sikap kerja dengan risiko tinggi pada kelompok kontrol dan $72.2 \%$ memiliki risiko rendah pada kelompok perlakuan. Selisih kadar asam laktat pada kelompok kontrol $(2.92 \mathrm{mmol} / \mathrm{kg})$ dan perlakuan $(0.51 \mathrm{mmol} / \mathrm{kg})$ dengan nilai $\mathrm{p}(0.000)$ menunjukan bahwa terdapat perbedaan pada kedua kelompok. Selisih kadar glukosa kelompok kontrol (4.94 $\mathrm{mg} / \mathrm{dL})$ dan kelompok perlakuan $(3.50 \mathrm{mg} / \mathrm{dL})$ dengan nilai $\mathrm{p}(0.000)$ menunjukan bahwa terdapat perbedaan kadar glukosa pada kedua kelompok. Disimpulkan bahwa peningkatan asam laktat dan berkurangnya glukosa pada pekerja dengan kursi ergonomis berbeda dengan pekerja tanpa kursi ergonomis yang berarti bahwa penggunaan kursi ergonomis mengurangi kelelahan pada perajin perak. Kata kunci: Kursi ergonomis, kelelahan kerja, kadar asam laktat, kadar glukosa
\end{abstract}

\begin{abstract}
Un Ergonomic work attitude is one of the causes of fatigue in silver crafters. This study aims to determine the effect of ergonomic chairs on the reduction of work fatigue based on the response of lactic acid and glucose in silversmiths. The design of this study is Quasi Experiment. With a total sample of 18 silversmiths in the control and treatment groups selected by random sampling. Data collected included work attitudes, levels of lactic acid and glucose before and after work. Data analysis in the form of Wilcoxon and Mann Whitney tests was used to test the effect of ergonomic chairs on decreasing work fatigue in silver crafters. The results showed that $30.6 \%$ of respondents were at $26-35$ years old. 50\% of respondents have a high risk work attitude in the control group and $72.2 \%$ have a low risk in the treatment group. Difference in lactic acid levels in the control group $(2.92 \mathrm{mmol} / \mathrm{kg})$ and treatment $(0.51 \mathrm{mmol} / \mathrm{kg})$ with a $\mathrm{p}$ value $(0.000)$ shows that there are differences in the two groups. Difference in glucose levels in the control group $(4.94 \mathrm{mg} / \mathrm{dL})$ and the treatment group $(3.50 \mathrm{mg} / \mathrm{dL})$ with a $\mathrm{p}$ value $(0.000)$ showed that there were differences in glucose levels in the two groups. It was concluded that increased lactic acid and reduced glucose in workers with ergonomic chairs differ from workers without ergonomic chairs, which means that the use of ergonomic chairs reduces fatigue in silversmiths.
\end{abstract}

Keywords: Ergonomic chair, fatigue at work, lactic acid levels, glucose levels 


\section{PENDAHULUAN}

Kesehatan dan keselamatan kerja atau K3 merupakan hal yang tidak terpisahkan dalam sistem ketenagakerjaan dan sumber daya manusia. Kesehatan dan keselamatan kerja tidak saja sangat penting dalam meningkatkan jaminan sosial dan kesejahteraan para pekerjanya akan tetapi akan jauh dari itu keselamatan dan kesehatan kerja berdampak positif atas berkelanjutan produktivitas kerjanya. Oleh karena itu kesehatan dan keselamatan kerja pada saat ini bukan sekedar kewajiban yang harus dipenuhi oleh para pekerja, akan tetapi juga harus dipenuhi oleh sebuah sistem pekerjaan. Dengan kata lain pada saat ini kesehatan dan keselamatan kerja bukan semata sebagai kewajiban, akan tetapi sudah menjadi kebutuhan bagi setiap para pekerja dan setiap bentuk pekerjaan.

Menurut Tarwaka (2004) pencapaian kesehatan dan keselamatan kerja tidak lepas dari ergonomi, karena telah menjadi tujuan penerapan dari ergonomi yaitu meningkatkan kesejahteraan fisik dan mental melalui upaya pencegahan cidera dan penyakit akibat kerja, menurunkan beban fisik dan mental, mengupayakan promosi dan kepuasan kerja. Pada penelitian di bidang ergonomi biasanya variabel terikat salah satunya menggunakan parameter kelelahan. Kondisi yang tidak melelahkan adalah kondisi yang nyaman. Bila suatu alat atau kondisi suatu hasil desain atau re-desain dibandingkan dengan sebelumnya kemudian diukur pada manusia penggunanya lebih tidak melelahkan berati alat atau kondisi tersebut lebih ergonomis. Kondisi yang cepat melelahkan adalah kondisi yanng tidak fisiologis. Bagaimana alat atau kondisi tersebut dibuat yang dapat berdampat pada manusia sehingga dapat bergerak secara fisiologis. Oleh karena itu, kondisi yang ergonomis adalah kondisi yang fisiologis (Santoso G, 2013).

Kelelahan merupakan bagian dari permasalahan umum yang sering dijumpai pada tenaga kerja terutama tenaga kerja dengan aktivitas manual handling. Kelelahan merupakan akumulasi berbagai aktivitas tubuh manusia yang menghasilkan kondisi tubuh yang ditandai dengan adanya perasaan lelah dan, konsentrasi menurun. Kelelahan juga dapat diartikan berupa suatu mekanisme perlindungan tubuh agar tubuh terhindar dari kerusakan lebih lanjut sehingga terjadi pemulihan setelah istirahat (Tarwaka dkk, 2004).

Dasar kata lelah (Fatigue) dari kata kelelahan menunjukan keadaan tubuh fisik dan mental yang berbeda tapi semuanya berakibat kepada penurunan daya kerja dan berkurangnya ketahanan tubuh untuk bekerja. Kelelahan dibagi dalam dua jenis yaitu kelelahan umum dan kelelahan otot. Kelelahan umum ditunjukkan oleh hilangnya kemauan untuk bekerja yang penyebabnya adalah keadaan persarafan sentral atau kondisi psikispsikologis. Akar masalah kelelahan umum 
adalah monotonnya pekerjaan, intensitas dan lamanya kerja mental dan fisik yang tidak sejalan dengan kehendak tenaga kerja yang bersangkutan, keadaan lingkungan yang berebeda dari estimasi semula, tidak jelasnya tanggung jawab, kekhawatiran yang mendalam dan konflik batin serta kondisi sakit yang diderita oleh tenaga kerja. Sedangkan kelelahan otot ditandai antara lain tremor atau rasa nyeri pada tremor (Suma'mur, 2009).

Berdasarkan pembagian kelelahan dalam proses dalam otot, kemudian kelelahan otot didefinisikan sebagai menurunnya kinerja sesudah mengalami stress tertentu yang ditandai dengan menurunnya kekuatan dan kelambatan gerak (Putri, 2008). Hal ini kemudian dibuktikan dengan hasil penelitian yang dilakukan oleh Wahyu (2011) pada karyawan unit logistik PT Indo Acidatama Tbk Kemiri Kebak kramat di Karanganyar yang menyatakan ada hubungan antara angkatangkut dengan kelelahan otot tangan karyawan yang menunjukkan menunjukkan bahwa responden berjumlah 20 orang, menunjukkan terjadinya penurunan kekuatan otot tangan rata-rata sebelum bekerja yakni $34,1 \mathrm{Kg}$ dan setelah bekerja mengalami penurunan kekuatan otot tangan yakni 30,3 Kg.

Sesuai dengan perkembangannya, terdapat beberapa cara pengukuran kelelahan. Pengukuran kelelahan biasa yang dipakai saatini menggunakan "angket kelelahan, flicker tension test, (Dewa, 2000 dalam Santoso, 2013). Angket kelelahan berupa lembar kertas birisi beberapa pertanyaan. Untuk flicker tension test dengan mengukur reaksi konsentrasi mata menangkap sinyal berupa sinar. Ada pula alat untuk mengukur kelelahan otot disebut electromyograf (EMG) yakni mengukur kontraksi otot. Kemudian Santoso pada tahun 2008 melakukan penelitian pada manusia (tenaga kerja) menguji kelelahan secara biologis menggunakan metabolisme energy anaerobic (MEA) konsentrasi asam laktat dan glukosa dalam darah. Sebelumnya asam laktat telah ditemukan untuk mengukur kelelahan pada hewan uji coba bukan untuk manusia (Santoso, 2013).

Beberapa kelelahan yang dialami oleh pengrajin diungkap oleh Susetyo (2008) yaitu : 1) Pelemahan kegiatan dengan presentase yang tinggi berupa lelah seluruh tubuh $(66,7 \%)$ dan kaki berat $(40 \%)$, 2) Lemah motivasi yaitu tidak dapat konsentrasi $(66,8 \%), 3)$ Kelelahan fisik berupa kekakuan di bahu $(66,7 \%)$, Nyeri di belakang kepala $(46,7 \%)$ dan nyeri punggung $(66,7 \%)$. Segala bentuk kelelahan yang dialami oleh pengrajin perak disebabkan oleh sikap kerja yang kurang alamiah dan intensitas lingkungan kerja yang belum memadai (Susetyo, Oes et al. 2008).

Berdasarkan hasil observasi menggunakan perhitungan REBA dalam penelitian (Nurhikmah 2011) yang berjudul Faktor-Faktor Yang Berhubungan Dengan Musculoskeletal Disorders (MSDs) Pada Pekerja Furnitur Di Kecamatan Benda Kota Tangerang di dapatkan tingkat risiko ergonomi 
tingggi pekerjaan (skor 8-10) yang dialami pekerja adalah 27 pekerja (33.3\%). Hasil uji statistik diketahui bahwa pekerja dengan tingkat risiko ergonomi Tinggi (skor 8-10) banyak mengalami Musculoskeletal Disorders yaitu sebanyak 22 orang atau $81.5 \%$ Berdasarkan hasil analisis bivariat berarti ada hubungan bermakna antara tingkat risiko ergonomi dengan Musculoskeletal Disorders.

Di Sulawesi Selatan tepatnya di Kota Makassar banyak terdapat pengrajin emas dan perak salah satunya yaitu berlokasi di Kelurahan Borong. Kelurahan Borong merupakan salah satu kelurahan yang berada diwilayah kerja Puskesmas Batua yang mata pencaharian sebagian besar terdiri dari pegawai, pengrajin, buruh harian dan sarana kesehatan Puskesmas Batua yang berada sekitar 4 (empat) $\mathrm{Km}$ dari kelurahan tersebut. Pada Kelurahan Borong tersebut terdapat dua RW yang sebagian besar bermata pencaharian pengrajing Emas dan Perak yaitu berada pada RW I dan RW II Borong.

Pada studi pendahuluan di lapangan sebagian besar sikap kerja pengrajin perak dan emas adalah sikap kerja statis yaitu sikap duduk di kursi menghadap meja dan punggung membungkuk, kaki kanan digunakan untuk menekan pompa kompor yang dipergunakan untuk mematri produk perhiasan. Sikap kerja ini dilakukan rerata 8-9 jam/hari dan sekalikali berdiri untuk mengambil sesuatu yang dibutuhkan termasuk waktu istirahat makan atau minum. Beban kerja statis ini menyebabkan kelelahan otot rangka disamping otot-otot mata karena harus selalu melihat benda kerja yang relatif kecil dan ini tergantung pada model perhiasaan yang diproduksi, beban kerja ini akan lebih parah lagi apabila lingkungan dan sikap kerja yang tidak ergonomi, dalam hal ini kesesuaian antara kursi dan meja yang membuat pengrajin tidak nyaman dalam melakukan pekerjaan.

Masyarakat pekerja perajin perak yang jumlahnya 43 orang di Kel. Borong ini memerlukan penanganan kesehatan yang baik agar tidak muncul masalah-masalah kesehantan kerja. Dari diskusi awal yang peneliti lakukan dengan salah satu pengrajin emas di kelurahan Batua kecamatan Manggala kota Makassar, yang bertujuan mencari data awal, dari hasil diskusi tersebut peneliti mendapatkan kesimpulan bahwa pengrajin tersebut sering mengalami nyeri pada punggung dikarenakan posisi kerja yang harus membungkuk, dan kondisi ini diperparah oleh kursi kerja yang tidak memiliki sandaran dan tidak sesuai dengan meja kerja sehinngga kondisi membungkuk tidak bisa dihindari dalam pekerjaanya. Hal ini menjadikan waktu kerja mereka lebih singkat karena dengan berbagai kegiatan yang dilakukan menjadikan pekerja cepat mengalami kelelahan secara subjektif.

Berdasarkan uraian latar belakang di atas, maka peneliti tertarik untuk melakukan penelitian pengaruh desain kursi kerja 
terhadap kelelahan pada pengrajin perak di kecamatan Manggala.

\section{BAHAN DAN METODE}

Penelitian ini dilakukan di industri rumah tangga yang bergerak dibidang pengrajin perak di Kecamatan Manggala dari Agustus sampai November 2016. Jenis Penelitian yang akan digunakan adalah Quasi Eksperiment. Populasi penelitian ini adalah seluruh pekerja industri rumah tangga yang bergerak dibidang pengrajin perak dikecamatan Manggala yang berjumlah 43 orang, pengambilan sampel dilakukan dengan cara random sampling berjumlah 38 orang.

Data yang dikumpulkan pada penelitian adalah data primer. Data diperoleh dari pengambilan sampel darah menggunakan Tools Kit untuk mendapatkan kadar asam laktat dan glukosa dalam darah. Analisis data yang digunakan untuk melihat selisih pre dan post pada kelompok perlakuan dan kontrol menggunakan mann whitney dan wilcoxon.

\section{HASIL}

\section{Umur}

Tabel 1.

Distribusi Responden Berdasarkan Kategori Umur Perajin Perak Kecamatan Manggala

\begin{tabular}{ccc}
\hline Kategori Umur & $\begin{array}{c}\text { Frekuensi } \\
\text { (n) }\end{array}$ & $\begin{array}{c}\text { Persen } \\
\text { (\%) }\end{array}$ \\
\hline $17-25$ tahun & 7 & 19.4 \\
$26-35$ tahun & 11 & 30.6 \\
$36-45$ tahun & 10 & 27.8 \\
$46-55$ tahun & 8 & 22.2 \\
\hline Total & $\mathbf{3 6}$ & $\mathbf{1 0 0 . 0}$ \\
\hline
\end{tabular}

Sumber : Data Primer, 2016
Tabel 1 menunjukan bahwa dari total 36 responden yang terbanyak terdapat pada range umur antara 26 - 35 tahun yaitu sebanyak 11 orang $(30.6 \%)$. Sedangkan dengan presentasi terkecil sebesar 19.4\% (7 orang) terdapat pada range umur 17 - 25 tahun, kelompok kontrol pada penelitian ini didominasi oleh kategori umur 26 - 35 tahun yaitu sebanyak 6 orang (33.3\%). sedangkan pada kelompok perlakuan jumlah responden terbanyak terdapat pada kategori umur 26 - 35 tahun dan 36 - 45 tahun dengan jumlah yang sama yaitu 5 orang perajin perak atau sebesar $27.8 \%$.

\section{Masa Kerja}

Tabel 2.

Distribusi Responden Berdasarkan Masa Kerja Perajin Perak Kecamatan Manggala

\begin{tabular}{lcc}
\hline $\begin{array}{c}\text { Kelompok } \\
\text { Responden }\end{array}$ & Mean \pm SD & $\begin{array}{c}\text { Frekuensi } \\
\text { (n) }\end{array}$ \\
\hline Kontrol & $22.22 \pm 7.803$ & 18 \\
Perlakuan & $17.28 \pm 9.863$ & 18 \\
\hline \multicolumn{1}{c}{ Total } & $\mathbf{1 9 . 7 5} \pm \mathbf{9 . 1 1 6}$ & $\mathbf{3 6}$ \\
\hline
\end{tabular}

Sumber : Data Primer, 2016

Rata-rata masa kerja paa kelompok sampel kontrol adalah 22.22 tahun, sedangkan pada sampel perlakuan memiliki nilai rata-rata yang lebih rendah yaitu 17.28 tahun menekuni pekerjaan sebagai perajin perak. Pembagian lama kerja responden berdasarkan nilai mean dikarenakan semua responden penilitian ini memiliki masa kerja $\geq 5$ tahun.

\section{Sikap Kerja}

Tabel 3 menunjukan bahwa perajin perak dengan sikap kerja risiko rendah paling besar berada pada kelompok sampel perlakuan yaitu sebesar $72 \%$ atau sebanyak 13 orang. 
Untuk perajin perak dengan sikap kerja risiko sedang dan tinggi dominan berada pada kelompok sampel kontrol sebanyak 9 orang $(50 \%)$.

Tabel 3.

Distribusi Responden Berdasarkan Sikap Kerja (Kategori Rula) Pada Perajin Perak Kecamatan Manggala.

\begin{tabular}{cccc}
\hline \multirow{2}{*}{ Sikap Kerja } & \multicolumn{2}{c}{ Kelompok responden } & \multirow{2}{*}{ Total } \\
\cline { 2 - 3 } & Kontrol & Perlakuan & \\
\hline Risiko Rendah & $0(0 \%)$ & $13(72.2 \%)$ & $13(36.1 \%)$ \\
Risiko Sedang & $9(50 \%)$ & $5(27.8 \%)$ & $14(38.9 \%)$ \\
Risiko Tinggi & $9(50 \%)$ & $0(0 \%)$ & $9(25 \%)$ \\
\hline Total & $\mathbf{1 8 ( 1 0 0 \% )}$ & $\mathbf{1 8 ( 1 0 0 \% )}$ & $\mathbf{3 6 ( 1 0 0 \% )}$ \\
\hline
\end{tabular}

Sumber : Data Primer, 2016

Tabel 4.

Uji Beda Anatara Kelompok Kontrol Dan Perlakuan Sebelum Dan Sesudah Intervensi Pada Pengukuran Asam Laktat

\begin{tabular}{|c|c|c|c|c|}
\hline \multirow{3}{*}{ Kelompok } & \multicolumn{3}{|c|}{ Asam Laktat } & \multirow{3}{*}{ Nilai $p^{*}$} \\
\hline & Sebelum & Sesudah & Selisih & \\
\hline & $\begin{array}{l}\operatorname{Mean} \pm \text { SD } \\
(\mathrm{mmol} / \mathrm{kg})\end{array}$ & $\begin{array}{c}\text { Mean } \pm \text { SD } \\
(\mathrm{mmol} / \mathrm{kg})\end{array}$ & $\begin{array}{l}\text { Mean } \pm \text { SD } \\
(\mathrm{mmol} / \mathrm{kg})\end{array}$ & \\
\hline Kontrol & $1.91 \pm 0.399$ & $4.83 \pm 0.593$ & $2.92 \pm 0.593$ & 0.000 \\
\hline Perlakuan & $1.82 \pm 0.424$ & $2.33 \pm 0.389$ & $0.51 \pm 0.232$ & 0.000 \\
\hline Nilai $p^{* *}$ & & & 0.000 & 0.000 \\
\hline
\end{tabular}

Sumber : Data Primer, 2016

Keterangan :

* Uji Wilcoxon

** Uji Mann Whitney

Tabel 5.

Uji Beda Anatara Kelompok Kontrol Dan Perlakuan Sebelum Dan Sesudah Intervensi Pada Pengukuran Glukosa

\begin{tabular}{lcccc}
\hline \multirow{3}{*}{ Kelompok } & \multicolumn{3}{c}{ Glukosa } & \\
\cline { 2 - 4 } & Sebelum & Sesudah & Selisih & \multirow{2}{*}{ Nilai p* } \\
\cline { 2 - 4 } & Mean \pm SD $(\mathbf{m g} / \mathbf{d L})$ & Mean \pm SD $(\mathbf{m g} / \mathbf{d L})$ & $\begin{array}{c}\text { Mean } \pm \text { SD } \\
(\mathbf{m g} / \mathbf{d L})\end{array}$ & \\
\hline Kontrol & $111.56 \pm 25.801$ & $106.61 \pm 25.984$ & $4.94 \pm 3.653$ & 0.000 \\
Perlakuan & $109.61 \pm 22.408$ & $106.11 \pm 22.916$ & $3.50 \pm 1.581$ & 0.000 \\
\hline \multicolumn{1}{c}{ Nilai $\mathbf{p}^{* *}$} & & & 0.471 & 0.000 \\
\hline Sunnnn
\end{tabular}

Sumber : Data Primer, 2016

Keterangan :

* Uji Wilcoxon

** Uji Mann Whitney 
Uji Beda Antara Kelompok Kontrol Dan Perlakuan Sebelum Dan Sesudah Intervensi Pada Pengukuran Asam Laktat

Tabel 4 diperoleh hasil kelompok kontrol pada awal pengukuran sebelum bekerja memiliki rerata nilai asam laktat 1.91 $\mathrm{mmol} / \mathrm{kg}$ dan pada pengukuran kedua setelah bekerja sebesar $4.83 \mathrm{mmol} / \mathrm{kg}$. Perubahan asam laktat pada kelompok kontrol sebesar $2.92 \mathrm{mmol} / \mathrm{kg}$. Dari hasil uji statistik diperoleh nilai $\mathrm{p}(0.000)<0.05$ yang berarti terdapat perbedaan antara pengukuran awal dan pengukuran akhir pada kelompok kontrol. Sedangkan pada kelompok perlakuan, pada pengukuran awal sebelum bekerja memiliki rerata nilai asam laktat $1.82 \mathrm{mmol} / \mathrm{kg}$ dan pada pengukuran kedua setelah bekerja sebesar 2.33 $\mathrm{mmol} / \mathrm{kg}$. Dari hasil uji statistik diperoleh nilai p $(0.000)<0.05$ yang berarti terdapat perbedaan antara pengukuran awal dan pengukuran akhir pada kelompok perlakuan.

\section{Uji Beda Antara Kelompok Kontrol Dan Perlakuan Sebelum Dan Sesudah Intervensi Pada Pengukuran Glukosa}

Tabel 5 diperoleh hasil kelompok kontrol pada awal pengukuran memiliki nilai glukosa $111.56 \mathrm{mg} / \mathrm{dL}$ dan pengukuran kedua sebesar $106.61 \mathrm{mg} / \mathrm{dL}$. Dari hasil uji statistik diperoleh nilai $p(0.000)<0.05$ yang berarti terdapat perbedaan antara pengukuran awal dan pengukuran akhir pada kelompok kontrol. Sedangkan pada kelompok perlakuan, pada pengukuran awal sebelum bekerja memiliki rerata glukosa sebesar $109.61 \mathrm{mg} / \mathrm{dL}$ dan pengekuran kedua setelah bekerja sebesar $106.11 \mathrm{mg} / \mathrm{dL}$. Dari hasil uji statistik diperoleh nilai $\mathrm{p}(0.000)<0.05$ yang berarti terdapat perbedaan antara pengukuran awal dan pengukuran akhir pada kelompok perlakuan.

\section{PEMBAHASAN}

Berdasarkan dari hasil penelitian pada tabel 2 diperoleh hasil bahwa terdapat peningkatan selisih asam laktat pada kelompok responden kontrol sebesar $2.92 \mathrm{mmol} / \mathrm{kg}$ dan perlakuan $0.51 \mathrm{mmol} / \mathrm{kg}$, namun peningkatan pada kelompok perlakuan lebih rendah dibandingkan dengan kelompok kontrol meskipun secara uji statistik memiliki hasil yang signifikan dengan nilai $\mathrm{p}(0.000)<0.05$. Hal ini membuktikan adanya pengaruh pemberian kursi ergonomis terhadap penurunan kelelahan dengan melihat rendahnya peningkatan asam laktat pada kelompok perlakuan pada perajin perak Kecamatan Manggala.

Hasil uji glukosa dalam darah sebelum dan sesudah melakukan pekerjaan pada tabel 4.6 diperoleh hasil bahwa selisih penurunan kadar glukosa dalam darah pada kelompok kontrol sebesar $4.94 \mathrm{mg} / \mathrm{dL}$ dan pada kelompok perlakuan $3.50 \mathrm{mg} / \mathrm{dL}$. Hasil uji statistik diperoleh nilai $\mathrm{p}(0.000)<0.05$. Dengan meningkatnya penurunan selisih kadar glukosa sebelum dan sesudah kerja pada responden kontrol lebih besar dari pada penurunan kadar glukosa pada responden 
perlakuan, menunjukan bahwa responden kontrol jauh lebih lelah dari pada responden perlakuan.

Meningkatnya kadar asam laktat dan menurunnya kadar glukosa dalam darah digunakan sebagai parameter kelelahan karena pada saat melakukan aktivitas kerja tidak ergonomis, tubuh memerlukan energi yang lebih banyak. Jumlah energi yang diperlukan tubuh tergantung dari intensitas aktivitas kerja yang dilakukan. Pada aktivitas kerja cukup ringan maka metabolisme penyediaan energi diproses secara aerobik, karena tersedia oksigen yang memadai. Namun, apabila intensitas kerja semakin meningkat, maka perlu penambahan energi secara anaerobik.metabolisme penyediaan energi anaerobik diproses dari pemecahan simpanan glikogen dalam otot sebagai bahan energi. Oleh karena itu, konsentrasi glikogen dalam otot menurun dan asam laktat meningkat. Peningkatan asam laktat akan menimbulkan kelahan sebagai mana menurut Anna (1994) dalam Santoso (2013) bahwa "Asam laktak banyak terjadi sehingga menimbulkan rasa lelah".

Berdasarkan data pada tabel 3, bahwa konsentrasi selisih nilai asam laktat hampir sama dengan nilai $1.91 \mathrm{mmol} / \mathrm{kg}$ pada kontrol dan $1.82 \mathrm{mmol} / \mathrm{kg}$. Hal ini memperlihatkan bahwa belum terjadi metabolisme anaerob pada tubuh untuk menghasilkan energi dan dari proses pembentukan energi tersebut menghasilkan asam laktat sebagai hasil buangan.

Terjadinya perubahan konsentrasi asam laktat dan glukosa sebelum dan sesudah kerja pada kelompok kontrol dan perlakuan sebelum dan sesudah bekerja dapat dijelaskan bahwa, sebelum bekerja melakukan aktivitas membuat kerajinan perak tubuh hanya membutuhkan energi untuk mempertahankan hidup. Namun, pada saat melakukan aktivitas sesuai dengan perlakuan kerja yang dilakukan, tubuh memerlukanenergi yang lebih banyak. Jumlah energi yang dibutuhkan tergantung dari intensitas aktivitas kerja yang dilakukan. Pada aktivitas kerja cukup ringan maka metabolisme penyediaan energi diproses secara anaerobik, karena tersedia oksigen yang memadai. Namun, apabila intensitas aktivitas kerja semakin meningkat, maka perlu penambahan energi secara anaerobik . Metabolisme penyediaan energi anaerobik diproses dari pemecahan simpanan glikogen dalam otot sebagai bahan energi. Oleh karena itu, konsentrasi glikogen dalam otot menurun dan asam laktat meningkat. Peningkatan asam laktat akan menimbulkan kelahan sebagai mana menurut Anna (1994) dalam Santoso (2013) bahwa "Asam laktak banyak terjadi sehingga menimbulkan rasa lelah".

Penjelasan mengenai metabolisme anaerob yang melibatkan glikogen dan menghasilkan asam laktat sebagai hasil akhir dari metabolis anaerob adalah hukum mengenai kerjamassa menyatakan bahwa 
waktu hasil reaksi kimia terbentuk pada media reaksi,kecepatan reaksi mendekati nol. Dua hasil akhir reaksi glikolisis adalah (1) asam piruvat dan (2) atom hidrogen, yang bergabung dengan NAD + membentuk NADH dan $\mathrm{H}^{+}$. Terbentuknya salah satu aatau kedua zat tersebut akan menghentikan proses glikolisis dan mencegah pembentukan ATP lebih lanjut. Untung, bila jumlah mulai berlebihan, kedua hasil akhir ini bereaksi satu sama lain membentuk asam laktat (Guyton, 1991).

Dari data pada tabel 1 menunjukan bahwa pada kategori sikap kerja dengan risiko tinggi terdapat pada kelompok perajin perak dengan kelompok kontrol. Itu berarti, kursi ergonomis yang diberikan pada responden dengan kelompok perlakuan memiliki dampak untuk mengurangi risiko ergonomis pada sikap kerja. Sikap kerja yang tidak ergonomis dapat meningkatkan kelelahan pada pekerja karena sikap paksa yang dilakukan menguras banyak energi. Hal ini sebanding dengan penelitian yang dilakukan oleh Susetyo (2008) pada perajin perak yaitu : 1) Pelemahan kegiatan dengan presentase yang tinggi berupa lelah seluruh tubuh $(66,7 \%)$ dan kaki berat (40\%), 2) Lemah motivasi yaitu tidak dapat konsentrasi (66,8\%), 3) Kelelahan fisik berupa kekakuan di bahu (66,7\%), Nyeri di belakang kepala (46,7\%) dan nyeri punggung $(66,7 \%)$. Segala bentuk kelelahan yang dialami oleh pengrajin perak disebabkan oleh sikap kerja yang kurang alamiah dan intensitas lingkungan kerja yang belum memadai (Susetyo, Oes et al. 2008).

Bentuk aktivitas dengan posisi dengan posisi kerja yang berbeda, jumlah otot yang diibatkan dan tenaga yang diperlukan juga berbeda (Santoso, 2013). Hang (2000) dalam Santoso (2013) menyebutkan bahwa otot yang terlibat untukmenahan pinggang berbeda antara ketika aktivitas berjalan atau memanjat tangga. Neptune (1998) dalam Santoso (2013) dalam hasil penelitiannya menyebutkan bahwa kuantitas performa otot dan non-otot (gravity dan velocity yang terkait dengan kekuatan) mempunyai konstribusi terhadap berbagai bagian tenaga dan akselarasi. Oleh karena itu, perajin perak yang melakukan aktivitas dan yang tidak melakukan aktivitas kerajinan perak memiliki jumlah kontraksi otot yang berbeda. Melakukan kerajinan perak tanpa menggunakan kursi ergonomis lebih banyak melibatkan intensitas kontraksi otot dan membutuhkan energi yang lebih banyak. Penyediaan energi tersebut disediakan melalui pemecahan ATP melalui metabolisme energi anaerobik. Becker (1999) dan Peter (1999) dalam Santoso (2013) menyebutkan bahwa "dalam metaboisme respirasi anaeerob hasil terbanyak reduksi asam piruvat adalah asam laktat. Kemudian hal tersebut dipertegas oleh Anna (1994) pada Santoso (2013) dan Guyton (1991) peningkatan asam laktat menimbulkan rasa lelah, dan kelelahan otot meningkat berbanding langsung dengan penurunan glikogen otot. Hal itu terbukti bahwa 
kelompok responden memiliki perbandingan asam laktat yang meningkat dan glukosa yang menurun pada pengukuran sebelum dan sesudah bekerja dengan nilai $\mathrm{p}(0.000)$ berarti terdapat perbedaan antara pengukuran sebelum dan sesudah bekerja.

\section{KESIMPULAN DAN SARAN}

Berdasarkan hasil penelitian pengaruh kursi ergonomis terhadap penurunan kelelahan pada perajin perak. Kadar asam laktat pada pekerja lebih rendah setelah menggunakan kursi ergonomis dibandingkan dengan pekerja tanpa kursi ergonomis. Hal ini dibuktikan dengan nilai selisih kenaikan asam laktat pada kelompok perlakuan $(0.51 \mathrm{mmol} / \mathrm{kg})$ lebih rendah dibandingkan kelompok kontrol (2.92 $\mathrm{mmol} / \mathrm{kg}$ ). Kadar glukosa lebih tinggi setelah penggunaan kursi ergonomis dibandingkan dengan pekerja tanpa kursi ergonomis. Ditunjukan dengan nilai selisih glukosa pada kelompok perlakuan $3,50 \mathrm{mg} / \mathrm{dL}$ dan kelompok kontrol $4.94 \mathrm{mg} / \mathrm{dL}$, hasil ini menunjukan bahwa penurunan glukosa pada kelompok perlakuan lebih sedikit dan penurunan glukosa pada kelompok kontrol lebih banyak. Peningkatan asam laktat dan berkurangnya glukosa pada pekerja dengan kursi ergonomis berbeda dengan pekerja tanpa kursi ergonomis. Hasil penelitian menunujukan bahwa selisih kadar asam laktat dan glukosa pada kelompok kontrol (2.92 $\mathrm{mmol} / \mathrm{kg} ; 4.94 \mathrm{mg} / \mathrm{dL}$ ) berbeda dengan kelompok perlakuan $(0.51 \mathrm{mmol} / \mathrm{kg} ; 3.50$ $\mathrm{mg} / \mathrm{dL}$ ). Adanya pengaruh positif terhadap pengrajin perak setelah pemberian kursi ergonomis untuk meningkatkan produktivitas kerja. Hal ini ditunujukan dengan pengukuran sikap kerja pada perajin perak yang mana pada kelompok perlakuan setalah diberikan kursi tidak terdapat responden dengan kategori sikap kerja berisiko tinggi dan pada responden dengan kategori kontrol terdapat kategori sikap kerja berisiko tinggi sebanyak 9 responden (50\%). Disarankan sebaiknya pengukuran asam laktat dan glukosa dilakukan dua kali sehingga mendapatka hasil yang lebih signifikan terhadap peniliaian kadar asam laktat dan glukosa.

\section{DAFTAR PUSTAKA}

Alvarado C.J. et al. (2005). Safety Climate and its Relationship to Self-reported Injury, Human Factors in Organizational Design and Management, Volume VIII, Elsevier, Amsterdam.

Cooper M.D. \& Phillips R.A. (2004). Exploratory Analysis of the Safety Climate and Safety Behavior Relationship, Journal of Safety Research, Volume 35, Elsevier, Amsterdam.

Depnaker RI. (2015). Indonesian Journal of Industrial Hygiene Occupational Health and Safety Volume XXIX No. 4, Jakarta: Depnaker.

Djatmiko R.D. (2016). Keselamatan dan Kesehatan Kerja, Edisi 1, Cetakan 1, Deepublish, Yogyakarta.

E.Bird Jr Frank. \& Germain. L. (1989). Practical Loss Control Leadership, International Loss Control Institute. 
Flin R. et al. (2010). Measuring Safety Climate : Identifying the Common Features, Safety Science, Volume 34, Elsevier, Amsterdam.

Hardiningsih \& Arisma Y. (2010). Kajian Model Epidemik SIR Deterministik Dan Stokastik Pada Waktu Diskrit. Jurnal. Surabaya: Institut Teknologi Sepuluh Nopember

Henning J.B. et al. (2009). The Influence of Individual Differences on Organizational Safety Attitudes, Safety Science, Volume 47, Elsevier, Amsterdam.

International Labour Office. (2003). Pencegahan Kecelakaan. Jakarta : PT Pustaka Binaman Pressindo

Priyatno D. (2009). SPSS untuk Analisis Korelasi, Regresi, dan Multivariate. Penerbit Gava Media, Yogyakarta.

PT. Jamsostek. (2015). Petunjuk Teknis Penyelesaian Jaminan (JKK, JHT, $J K)$, Jakarta:

Sekar A.P. (2013). Perbandingan tingkat kinerja keselamatan dan kesehatan kerja sebelum dan sesudah penerapan ohsas 18001 di pt. Phapros, tbk., Jurnal Studi Manajemen \& Organisasi Volume 10 , Nomor 2, Juli, Tahun 2013, Halaman 99-120.

Weick K. et al. (2009). Organizing for High Reliability : Processes of Collective Mindfulness, Research in Organizational Behaviour, Volume 1, Stanford Jai Press, California. 